\title{
Differentiation of Frankia strains by their electrophoretic patterns of intracellular esterases and aminopeptidases
}

\author{
MiNA G. Z. GIRGIS ${ }^{1,2}$ and JAIME SCHWENCKE ${ }^{1,3 *}$ \\ ${ }^{1}$ Laboratoire de Biotechnologie des Symbioses Forestières Tropicales, ORSTOM/CIRAD-Foret, 45 Bis Avenue de la \\ Belle Gabrielle, 94736, Nogent-sur-Marne, France \\ ${ }^{2}$ Unit of Biofertilizers, Microbiology Department, Faculty of Agriculture, Ain Shams University, Cairo, Egypt \\ ${ }^{3}$ Laboratoire d' Enzymologie, CNRS, 91198 Gif-sur-Yvette, France
}

(Received 19 October 1992; revised 17 February 1993; accepted 18 March 1993)

\begin{abstract}
The closely related Frankia strains BR, S21 and Thr, isolated from the genus Casuarina, Allo2 and Dec from the genus Allocasuarina, and G80 from the genus Gymnostoma, could be distinguished by their esterase zymograms after ultra-low gelling point agarose-polyacrylamide electrophoresis. The kanamycin-resistant derivatives S21-kR and BR-kR could also be differentiated from their kanamycin-sensitive parental strains. Different patterns of intracellular esterases could be obtained by using $\beta$-naphthyl propionate or 3 -indoxyl acetate as substrates. The substrate 5-bromo-4-chloro-3-indoxyl acetate proved particularly useful, revealing a variety of esterases from Gymnostoma isolates. Zymograms of aminopeptidases from all strains were found to be quite similar. Nevertheless, they allowed differentiation of Frankia strains BR and S21 from their kanamycin-resistant derivatives. Aminopeptidase and esterase zymograms obtained from Gymnostoma isolates were markedly different from all others. Zymograms of esterases and aminopeptidases may prove useful for the identification of some other Frankia strains.
\end{abstract}

\section{Introduction}

Trees of the family Casuarinaceae are widely used in agroforestry because of their association with the actinomycete Frankia, which can fix atmospheric nitrogen at rates comparable to the rhizobia of nodulated legumes (Torrey, 1978; Dommergues, 1987). The family Casuarinaceae is divided into four genera: Casuarina sensu stricto (18 species), Allocasuarina (58 species), Gymnostoma (18 species) and Ceuthostoma (2 species) (Johnson, 1988). All Frankia-type isolates are now classified within the genus Frankia (Becking, 1970). The general characteristics of all Frankia strains have been recently reviewed by Akkermans et al. (1992). Improved use of the Frankia-plant symbiosis implies not only

\footnotetext{
* Author for correspondence (at ORSTOM/CIRAD-Forêt, Nogent sur-Marne). Tel. 1439444 10; fax 143944329 .

Abbreviations: BCA, bicinchoninic acid; BCIA, 5-bromo-4-chloro-3indoxyl acetate; MNA, 4-methoxy $\beta$-naphthylamide; ULGA, ultra-low gelling point agarose; $R_{\text {fum }}$, ratio obtained by dividing the electrophoretic migration of a given esterase activity by the migration of prestained fumarase.
}

laboratory selection of optimally performing strains, but also tests in field conditions, for which consideration of properties such as persistence in the soil and good competitiveness of the released strains is essential. Studies to examine these properties require techniques to identify and follow individual strains after their release (Simonet et al., 1990).

Various methods have been proposed to characterize and identify Frankia strains: the use of antisera, restriction analysis of the genome and specific DNA or RNA, determination of fatty acid composition and SDSPAGE analysis of whole cell protein patterns all have their usefulness and limitations, and have been discussed and reviewed (Nazaret et al., 1989; Mirza et al., 1991; Akkermans et al., 1992; Baker \& Mullin, 1992). However, identification of Frankia strains by relatively simple, low-cost and reliable methods, which discriminate between closely related strains such as those isolated from trees of the family Casuarinaceae, has not been possible up to now.

The use of non-denaturing ultra-low gelling point agarose-polyacrylamide gel electrophoresis (ULGAPAGE), as described by Benoist \& Schwencke (1990), revealed diverse but reproducible patterns (zymograms) 
of aminopeptidases, dehydrogenases and esterases for Frankia strains. Previous studies have indicated that the electrophoretic analysis of enzymes patterns was a promising technique for analysis of the diversity of Frankia strains (Gardes \& Lalonde, 1987; Prin et al., 1991), but was limited by problems related to the heterogeneous nature of the Frankia cultures used (simultaneous presence of sporangia, lysing hyphae, growing hyphae and dead hyphae) resulting from nonbalanced growth.

Here we show that by using cells grown in controlled agitated conditions in mineral medium (BAP) supplemented with egg yolk phosphatidylcholine (BAP-PCM), reproducible zymograms of esterases and aminopeptidases were obtained for every strain, allowing the strains to be differentiated.

\section{Methods}

Isolation of Frankia Allo2. Frankia Allo2 was isolated from young nodules formed on Allocasuarina verticillata plants after inoculation under greenhouse conditions with dried nodule samples collected in Uruguay. Nodule lobes were superficially sterilized in a $2 \%(\mathrm{w} / \mathrm{v})$ aqueous solution of osmium tetroxide (Lalonde et al., 1981) for $3 \mathrm{~min}$. Nodule lobes were then thoroughly rinsed in sterile water, chopped into small pieces and transferred into a double-layer agar medium as recommended by Diem \& Dommergues (1983). After 4 weeks, Frankia colonies grew out of nodule pieces and exhibited typical hyphae and sporangia. Nitrogen-fixing vesicles developed on nitrogen-free medium. Nodulation tests of the isolate were made on seedlings of the original host grown in tubes or sand culture. Infection tests showed that Allo2 was infective and effective in nitrogen fixation on species of genera Allocasuarina (verticillata and decaisneana) and Casuarina (glauca and equisetifolia).

Bacterial strains and growth conditions. The origin and designation of Frankia isolates are described in Table 1. Cultures of all Frankia

Table 1. Origin of Frankia isolates used in this study

\begin{tabular}{|c|c|c|c|}
\hline $\begin{array}{l}\text { Trivial } \\
\text { designation }\end{array}$ & Original host & $\begin{array}{l}\text { Geographical } \\
\text { origin }\end{array}$ & Reference \\
\hline BR & Casuarina equisetifolia & Brazil & $\begin{array}{l}\text { Müller et al } \\
\text { (1991) }\end{array}$ \\
\hline BR-kR & Casuarina equisetifolia & Brazil & $*$ \\
\hline $\mathbf{S} 21$ & Casuarina glauca & Egypt & $\begin{array}{c}\text { Girgis et al. } \\
(1990)\end{array}$ \\
\hline S21-kR & Casuarina glauca & Egypt & * \\
\hline Thr & Casuarina cunninghamiana & Egypt & $\begin{array}{c}\text { Girgis et al. } \\
(1990)\end{array}$ \\
\hline Allo2 & Allocasuarina verticillata & Uruguay & This paper \\
\hline Dec & Allocasuarina decaisneana & Senegal & $\begin{array}{c}\text { Sougoufara } \\
(1990)\end{array}$ \\
\hline G80 & Gymnostoma nobilis & Singapore & + \\
\hline
\end{tabular}

* S21-kR and BR-kR, kanamycin-resistant derivatives of isolates BR and S21 (M. Girgis, J. Schwencke, A. Akkermans \& E. Duhoux, unpublished).

† A. Savouré \& G. Lim, unpublished. isolates were stored in complete $\mathrm{Q}_{\bmod }$ medium (Lalonde \& Calvert, 1979) supplemented with $50 \mu \mathrm{g}$ kanamycin $\mathrm{ml}^{-1}$ for the kanamycinresistant isolates BR-kR and S21-kR. Inocula of Frankia were prepared by washing the culture twice with sterile $0.85 \% \mathrm{NaCl}$, and passing through a sterile syringe needle $(0.6 \times 30 \mathrm{~mm})$; this material was inoculated at $1 \mu \mathrm{g}$ protein $\mathrm{ml}^{-1}$ (Bradford, 1976) into BAP medium (Fontaine et al., 1986) supplemented with egg yolk phosphatidylcholine mixture (P-4279 from Sigma; $1.7 \mu \mathrm{g} \mathrm{I}^{-1}$ ) instead of soybean phosphatidylcholine mixture (P-3644 Sigma) and buffered with MES/Tris (10 mM, pH 6.8) [BAP-PCM medium as described by Schwencke (1991)]. This minimized post-exponential decrease in biomass during the early stationary phase. Isolates BR-kR and S21-kR were grown under the same conditions except that BAP-PCM medium was supplemented with $50 \mu \mathrm{g}$ kanamycin $\mathrm{ml}^{-1}$. Three pre-cultures were grown at $28^{\circ} \mathrm{C}$ and magnetically stirred (200 r.p.m.). Mycelial cells were harvested and the cellular protein determined periodically by the Bradford (1976) method

Preparation of bacterial extract and protein determination. After $5 \mathrm{~d}$ growth at $28^{\circ} \mathrm{C}$, cultures were centrifugated at $4000 \mathrm{~g}$ for $15 \mathrm{~min}$ in a swinging-bucket rotor. The pellets were washed twice with BAPPCM medium and once with cold lysis buffer $(20 \mathrm{~mm}-\mathrm{Tris} / \mathrm{HCl}$, $\mathrm{pH} 7.5,100 \mathrm{~mm}-\mathrm{KCl}, 5 \%, \mathrm{w} / \mathrm{v}$, glycerol). Then, $3 \mathrm{ml}$ of cold lysis buffer was added to 1 gram (wet weight) of pelleted cells and the suspension $(20 \mathrm{~W}$; Branson Sonifier 250$)$ sonicated eight times for 2 min at $-20{ }^{\circ} \mathrm{C}\left(\mathrm{CaCl}_{2} / \mathrm{ice}\right)$. The homogenates were ultracentrifuged $\left(186000 \mathrm{~g}, 60 \mathrm{~min}, 4^{\circ} \mathrm{C}\right)$ and the supernates (cytosolic crude extracts) carefully collected. Glycerol was added to a final concentration of $10 \%$ $(\mathrm{w} / \mathrm{v})$. Protein concentration of cytosolic crude extracts was determined by the BCA (bicinchoninic acid) method according to the manufacturer's (Pierce) instructions, using bovine serum albumin as a standard. Cytosolic crude extracts were used immediately or after $2 \mathrm{~d}$ storage at $-80^{\circ} \mathrm{C}$

Electrophoretic conditions. Vertical, non-denaturing slab electrophoresis was performed in mixed agarose-polyacrylamide gels (Benoist \& Schwencke, 1990). Resolving gels $(135 \times 130 \times 2.0 \mathrm{~mm})$ contained $7 \%$ acrylamide (Serva), $0 \cdot 186 \%$ bisacrylamide, $0.4 \%$ ultra-low gelling point agarose (ULGA) from FMC Bioproducts, $0.375 \mathrm{M}$-Tris $/ \mathrm{HCl}$, pH $8.8,0.075 \%$ ammonium persulphate, and $0.03 \%$ (v/v) TEMED $\left(N, N, N^{\prime \prime}, N^{\prime \prime}\right.$-tetramethylethylenediamine) from Serva. Stacking gels contained $4.5 \%$ acrylamide, $0.225 \%$ bisacrylamide, $0.2 \%$ ULGA, $0.125 \mathrm{M}$-Tris/ $\mathrm{HCl}, \mathrm{pH} 6.8,0.075 \%$ ammonium persulphate and $0.07 \%$ (v/v) TEMED. Acrylamide polymerization was allowed to proceed at room temperature, then gelling was completed by cooling to $4^{\circ} \mathrm{C}$ for $30 \mathrm{~min}$. Gels were pre-electrophoresed twice with running buffer $(0.050 \mathrm{M}$-Tris $/ 0.384 \mathrm{M}$-glycine, $\mathrm{pH} 8.3)$ for $15 \mathrm{~min}$ at $40 \mathrm{~mA}\left(4^{\circ} \mathrm{C}\right)$. The running buffer was supplemented with $50 \mu \mathrm{m}-\mathrm{CoSO}_{4}$ or $50 \mu \mathrm{M}-\mathrm{ZnSO}_{4}$ for aminopeptidase or $5 \mathrm{~mm}-\mathrm{MgCl}_{2}$ for esterase detection. Samples from crude cytosolic extracts containing $100-300 \mu \mathrm{g}$ protein (determined by the BCA method) were electrophoresed at $25 \mathrm{~mA}$ constant current $\left(4^{\circ} \mathrm{C}\right)$ for $5 \mathrm{~h}$. A prestained fumarase was used as a marker for migration.

Detection of esterases. After electrophoresis, the gels were equilibrated by gently shaking for $30 \mathrm{~min}$ with $100 \mathrm{ml} 100 \mathrm{mM}-\mathrm{HEPES} / \mathrm{KOH}$, $\mathrm{pH} 7.5,100 \mathrm{~mm}-\mathrm{NaCl}, 5 \mathrm{~mm}-\mathrm{MgCl}_{2}$. The gels were then placed in plastic bags, substrates added from a $200 \mathrm{~mm}$ stock solution in DMSO, and Fast Garnet GBC added to $0.025 \%$ final concentration; the plastic bags were closed and shaken in the dark at room temperature for $30 \mathrm{~min}$. Three different substrates ( $1 \mathrm{~mm}$ final concentration; all from Sigma) were used: $\beta$-naphthyl propionate, 3 -indoxyl acetate and 5 bromo-4-chloro-3-indolyl acetate (BCIA). Esterases appeared as brown, red or blue-green bands with the three substrates respectively. A commercial (Sigma) acetylcholine esterase (AchE) ( $1 \mu \mathrm{g}$ ) was detectable after 5 min of incubation. 
Detection of aminopeptiduses. The assay was essentially as described by Benoist \& Schwencke (1990) with the following modifications. After electrophoresis, gels were equilibrated by gently shaking for $30 \mathrm{~min}$ with $100 \mathrm{ml} 100 \mathrm{~mm}-\mathrm{HEPES} / \mathrm{KOH}, \mathrm{pH} 70,200 \mu \mathrm{m}-\mathrm{CoSO}_{4}, 200 \mathrm{~mm}-$ $\mathrm{NaCl}$. The gels were placed into plastic bags with $20 \mathrm{ml} 50 \mathrm{~mm}$-MES$\mathrm{KOH}, 50 \mathrm{~mm}$ TES-KOH, pH 7.0,1 mM substrate (from a $200 \mathrm{~mm}$ stock solution in DMSO), $200 \mu \mathrm{M}-\mathrm{CoSO}_{4}$ and $200 \mathrm{~mm}-\mathrm{NaCl}$. Two different substrates were used, L-leucine-4-methoxy- $\beta$-naphthylamide (L-LeuMNA) or L-Pro-MNA from Bachem (Dübendorf, Switzerland). Freshly prepared Fast Garnet GBC coupling agent was added at $0-025 \%$ final concentration and the bags were then closed, and shaken for $10 \mathrm{~min}$ at room temperature. Red (L-Leu-MNA) or orange (L-Pro-MNA) bands corresponding to aminopeptidase activities usually appeared after 5 min of incubation. Incubations were done in the dark at room temperature and were stopped by immersing the gels in $10 \%(\mathrm{v} / \mathrm{v})$ acetic acid for 30-60 min. The gels were then washed twice for $20 \mathrm{~min}$ with distilled water. In these conditions, a reasonably clear background was obtained without band destaining or gel cracking during drying at $70^{\circ} \mathrm{C}$. The relative mobility of bands was calculated as $R_{\text {fum }}$ values, which were obtained by dividing the distance $(\mathrm{mm})$ travelled by a given esterase by the distance $(\mathrm{mm})$ travelled by prestained fumarase as a marker.

\section{Results}

Growth characteristics of Frankia isolates in supplemented BAP medium

For growth of all Frankia strains in BAP-PCM medium under stirring, the optimal concentration of the egg yolk phosphatidylcholine supplement was $1 \cdot 7 \mu \mathrm{gl}^{-1}$ (Fig. 1 a). The complete $Q_{\text {mod }}$ medium (buffered with $10 \mathrm{~mm}$ MES/Tris) allowed balanced growth until day 4 but maximal biomass yield was about one-sixth of that obtained in mineral medium BAP-PCM. All strains used in this study grew exponentially in BAP-PCM as shown in Fig. 1 (b) for strains S21, Thr and Dec, indicating that nutritional conditions were optimal. As shown in Table 2, maximal mycelial growth was obtained at day 5 for all Frankia isolates tested. Except for BR-kR and
G80, a biomass yield of $17-22 \mu \mathrm{g}$ protein $\mathrm{ml}^{-1}$ was obtained for all strains.

\section{Electrophoretic patterns of esterases}

Zymograms of esterases revealed by 3-indoxyl acetate. Zymograms of esterases obtained using 3-indoxyl acetate are shown in Fig. 2(a). Isolates BR, Thr and Allo2 could not be clearly differentiated using this substrate, while all the other isolates showed a characteristic pattern of isoenzymes. Thus, strain Dec presented a unique band, $R_{\text {fum }} 0.23$. The Gymnostoma strain G80 showed three fast migrating bands, $R_{\text {fum }} 0.58,0.78$ and 1.22 , that were not detected in strains from Casuarina and Allocasuarina. Further, the esterase zymograms of the kanamycinresistant derivatives BR-kR and S21-kR (Fig. 2d) were

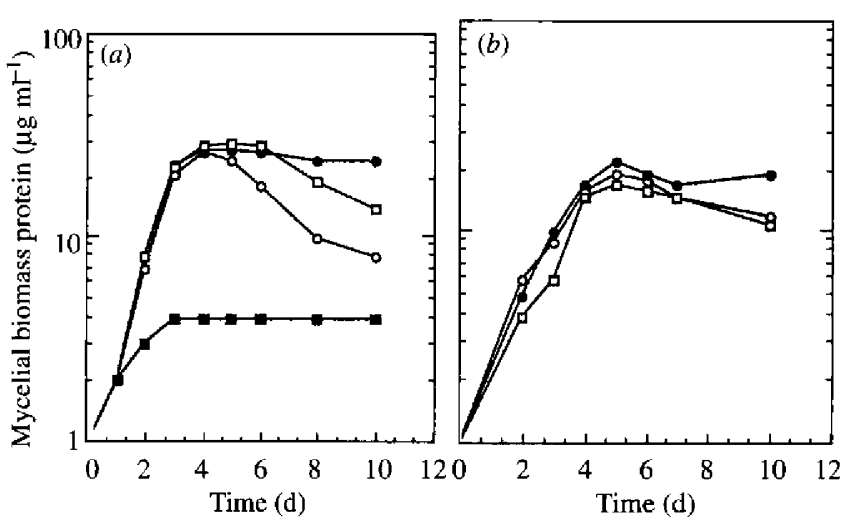

Fig. 1. Growth kinetics of Frankia strains. (a) Effect of different phosphatidylcholines on growth of strain BR in buffered BAP-PCM, supplemented with soybean phosphatidylcholine $\left(3 \cdot 4 \mu \mathrm{g} \mathrm{ml}^{-1}, O\right)$ or egg yolk phosphatidylcholine $\left(3.4 \mu \mathrm{g} \mathrm{ml}^{-1}, \square ; 1.7 \mu \mathrm{g} \mathrm{m} l^{-1}\right.$, pared with growth in the rich medium $Q_{\bmod }$ buffered with MES/Tris (ם). (b) Growth of Frankia strains in buffered BAP-PCM medium supplemented with egg yolk phosphatidylcholine $\left(1 \cdot 7 \mu \mathrm{g} \mathrm{ml}^{-1}\right) . \mathrm{O}, \mathrm{S} 21$; อ. Thr; $\square$, Dec.

Table 2. Biomass yield of Frankia isolates growing in stirred, buffered BAPPCM medium supplemented with egg yolk phosphatidylcholine

See Methods for details. Cultures were inoculated with $1 \mu \mathrm{g}$ protein $\mathrm{ml}^{-1}$. Each value is the mean of three replicates.

\begin{tabular}{crrrrrrrr}
\hline \hline & \multicolumn{7}{c}{ Biomass obtained $\left(\mu \mathrm{g} \text { protein } \mathrm{ml}^{-1}\right)^{*}$} \\
\cline { 2 - 8 } $\begin{array}{c}\text { Frankia } \\
\text { isolate } \ldots\end{array}$ & S21 & S21-kR† & BR & BR-kR† & Thr & Allo2 & Dec & G80 \\
\hline $\begin{array}{c}\text { Time (d) } \\
4\end{array}$ & 15.86 & 17.34 & $\mathbf{1 6 . 3 6}$ & 9.50 & 17.32 & 19.64 & 15.04 & 8.00 \\
$\mathbf{5}$ & $\mathbf{1 8 . 9 1}$ & $\mathbf{2 0 . 2 4}$ & $\mathbf{1 7 . 0 6}$ & $\mathbf{1 2 . 9 1}$ & $\mathbf{2 2 . 3 8}$ & $\mathbf{2 1 . 4 0}$ & $\mathbf{1 6 . 6 5}$ & $\mathbf{1 5 . 9 2}$ \\
6 & 17.66 & 16.50 & 16.53 & 11.26 & 18.88 & 16.00 & 16.12 & 13.57 \\
\hline \hline
\end{tabular}

* Determined by the Bradford (1976) method.

$\doteqdot$ Kanamycin-resistant derivatives of BR and S21 respectively (M. Girgis, J. Schwencke, A. Akkermans \& E. Duhoux, unpublished results). 
(a)

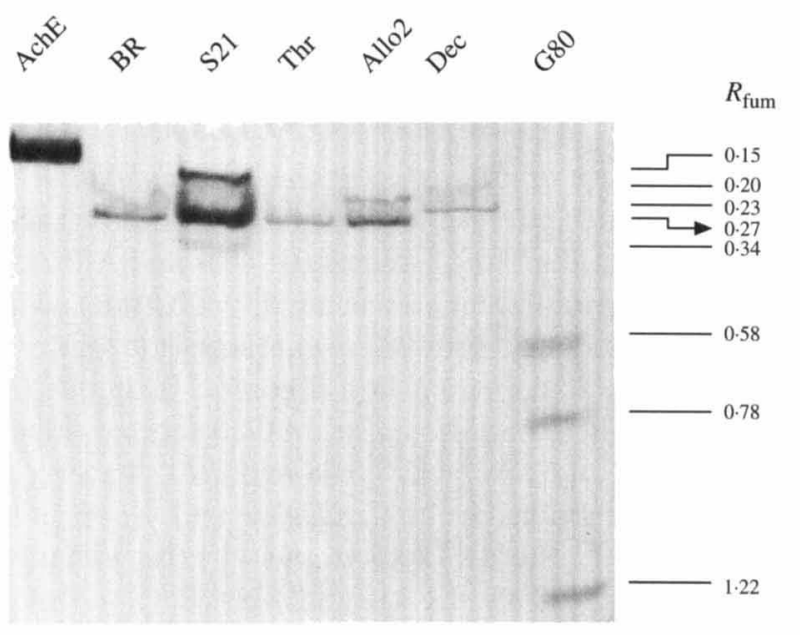

(c)

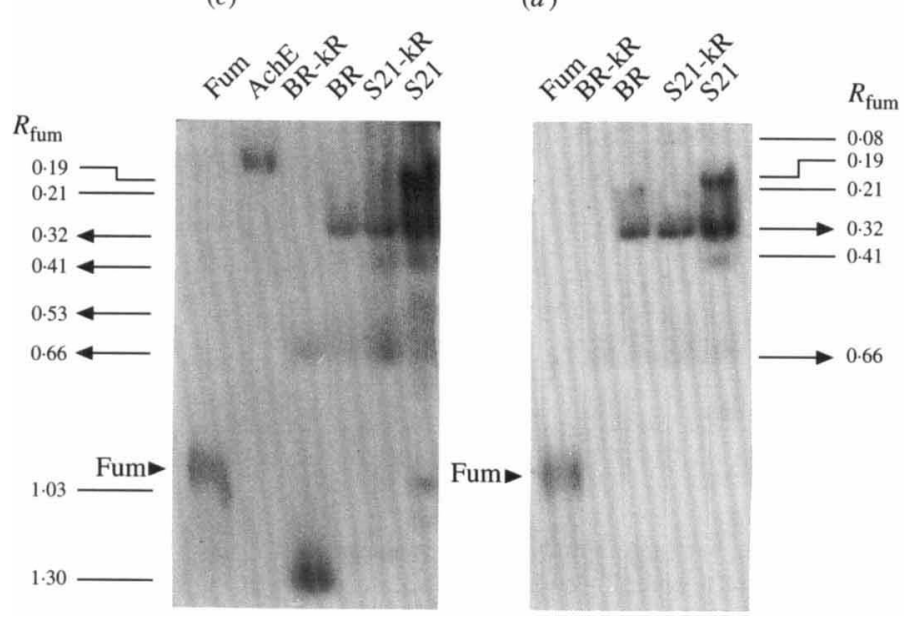

(b)

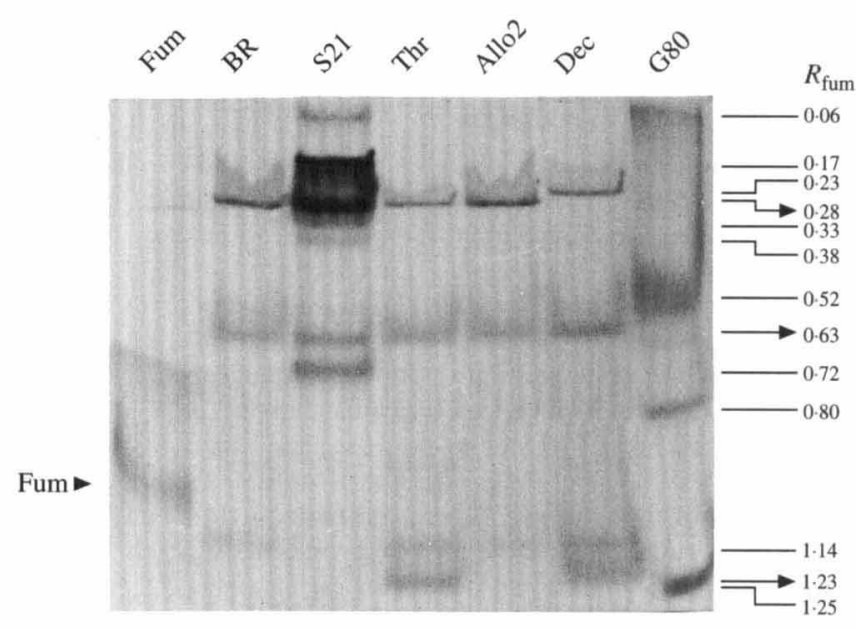

(e)

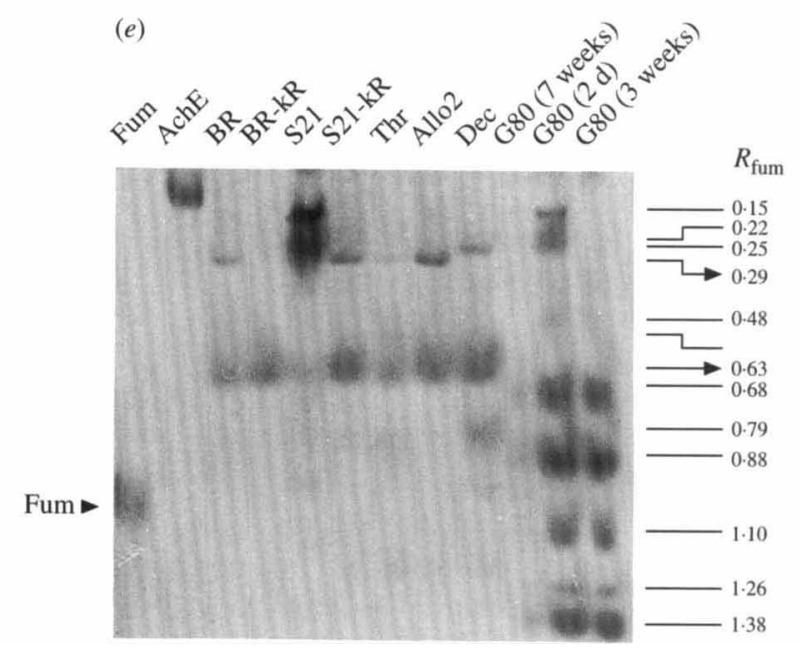

Fig. 2. Electrophoretic patterns for esterases of some Frankia strains. For each Frankia strain $250 \mu \mathrm{g}$ protein (BCA method) were loaded. Fum, prestained fumarase marker. $R_{\text {fum }}$, mobility calculated with reference to that of prestained fumarase. Gels were incubated with $1 \mathrm{~mm}$-3-indoxyl acetate, $5 \mathrm{~mm}-\mathrm{MgCl}_{2}(a, d), 1 \mathrm{~mm} \beta$-naphthyl propionate, $5 \mathrm{~mm}-\mathrm{MgCl}_{2}(b, c)$ or $1 \mathrm{~mm}-\mathrm{BCIA}, 5 \mathrm{~mm}-\mathrm{MgCl}_{2}(e)$.

different from those of their original sensitive parental strains BR and S21. Thus, while two bands, $R_{\text {fum }} 0.19$ and 0.41 , were characteristic for strain S21, they could not be detected in S21-kR. Also, a new very weak band, $R_{\text {fum }}$ 0.08 , was detected only in $S 21-\mathrm{kR}$. In addition, the parental strain BR showed two bands, $R_{\text {fun }} 0.21$ and 0.32 , but neither was detected in its kanamycin-resistant derivative BR-kR.

Zymograms of esterases revealed by $\beta$-naphthyl propionate. Strain S21 showed six bands of esterase activity (Fig. $2 b$ : two strong bands, $R_{\text {fum }} 0.17$ and 0.28 , and five weak bands, $R_{\text {fum }} 0.06,0.33,0.38$ and 0.72 . The esterase bands of $R_{\text {fum }} 0 \cdot 06,0 \cdot 17,0.33$ and 0.72 were present only in strain S21, allowing it to be differentiated from all other strains. Strains BR and Thr could not be differentiated using this substrate since they presented a very similar isoenzyme pattern. Strain Dec showed a characteristic band, $R_{\text {furm }} 0 \cdot 23$, which allowed it to be differentiated from all other strains. The Gymnostoma strain G80 was easily differentiated from all others by bands of $R_{\text {fum }} 0.52$ and 0.80 .

Zymograms of esterases revealed by BCIA. This substrate, which has not been previously used for the detection of Frankia esterases, revealed a variety of esterases from the Gymnostoma strain G80. Seven characteristic main bands were clearly detected, $R_{\text {fum }}$ $0 \cdot 15,0 \cdot 22,0 \cdot 68,0 \cdot 88,1 \cdot 10,1 \cdot 26,1 \cdot 38$ (Fig. $2 d, e$ ), and a weak band, $R_{\text {fun }} 0 \cdot 48$. Using 3 -indoxyl acetate (Fig. $2 a$ ) or $\beta$-naphthyl propionate (Fig. $2 b$ ) revealed only three clearly defined bands for strain G80. All other strains from Casuarina or Allocasuarina showed rather similar esterase patterns with BCIA. However, strain S21 
showed two bands, $R_{\text {fum }} 0 \cdot 15$ and 0.22 , which allowed it to be differentiated from all other strains. Also, strain Dec showed a characteristic band, $R_{\text {fum }}$ 0.79. Clear differences were also found between the parental strains S21 and BR, and their kanamycin-resistant derivatives BR-kR and S21-kR. Thus, the band of $R_{\text {fum }} 0.29$ present in strain BR was absent in BR-kR. Similarly, the strong bands of $R_{\text {fum }} 0.15$ and 0.25 present in S21 were absent in S21-kR, which showed instead bands of $R_{\text {fum }} 0.29$ and $0 \cdot 63$; the latter was seen only faintly in strain S21.

\section{Effect of storage on the pattern of esterases and aminopeptidases}

For all experiments we used late exponentially growing cells ( $5 \mathrm{~d}$ old) and fresh extracts, or extracts stored for up to $2 \mathrm{~d}$ at $-80^{\circ} \mathrm{C}$. This is because extracts stored for more than 1 week showed an altered pattern of esterases, as shown in Fig. 2(e) for Gymnostoma extracts stored at $-80^{\circ} \mathrm{C}$ for $2 \mathrm{~d}$ and 3 or 7 weeks. The maximum activity of esterases was obtained with the 2-d-old extract. Seven well-defined bands were detected, $R_{\text {fum }} 0 \cdot 15,0 \cdot 22,0 \cdot 68$, $0 \cdot 88,1 \cdot 10,1 \cdot 26$ and $1 \cdot 38$. This pattern remained unaltered for 1 week (not shown). Analysis of extracts after a 3 week storage period at $-80^{\circ} \mathrm{C}$ showed that the bands of $R_{\text {fum }} 0.15$ and 0.22 were no longer detectable, while after storage for 7 weeks, only four weak bands could be visualized, $R_{\text {fum }} \cdot 0 \cdot 68,0 \cdot 88,1 \cdot 10$ and $1 \cdot 38$. Similarly, some aminopeptidase activities were also sensitive to storage, as seen in Fig. 3(a).

\section{Aminopeptidase enzyme patterns}

Similar aminopeptidase patterns for Casuarina and Allocasuarina strains (Fig. $3 a$ ) were obtained when extracts were electrophoresed in the presence of $\mathrm{CoSO}_{4}$ and bands in the gel revealed using L-Leu-MNA as substrate in the presence of $\mathrm{CoSO}_{4}$ and $\mathrm{NaCl}$. Only strain $\mathrm{S} 21$ could be differentiated from other strains because it showed clearly separated bands, $R_{\text {fum }} 0.79,0.82$ and 0.94 , in a zone where all others showed diffuse bands. No other clear difference was revealed in these conditions for extracts of Frankia strains from the genera Casuarina and Allocasuarina. Strain G80 from the genus Gymnostoma gave a quite different aminopeptidase zymogram with three typical bands, $R_{\text {fum }} 0.26,0.32$ and 0.99 (Fig. $3 a ;$ G80 2 d). Band $R_{\text {fum }} 0 \cdot 26$ was undetectable in 3-weekold extracts.

As seen in Fig. 3(b), all strains from Casuarina and Allocasuarina showed a single, common aminopeptidase band, $R_{\text {fum }} 0.86$, when $\mathrm{ZnSO}_{4}(50 \mu \mathrm{M})$ was present during electrophoresis and bands in the gel revealed using $\mathrm{L}$ Leu-MNA as substrate in the presence of $\mathrm{CoSO}_{4}$ and $\mathrm{NaCl}$. The Gymnostoma strain G80 showed two different bands: a strong band, $R_{\text {fum }} 0 \cdot 94$, and a weak band, $R_{\text {fum }}$ $0 \cdot 31$.

Finally, all the strains from the genera Casuarina and Allocasuarina showed similar patterns when $\mathrm{CoSO}_{4}$ was present during electrophoresis and aminopeptidase activities were revealed using L-Pro-MNA as substrate in the presence of $\mathrm{CoSO}_{4}$ and $\mathrm{NaCl}$ (Fig. 3c). However, strain S21 could be clearly differentiated from its kanamycin-resistant derivative $\mathrm{S} 21-\mathrm{kR}$ because it showed an AP band of $R_{\text {fum }} 0.22$ that was absent in S21. No clear differences could be observed between strain $B R$ and its kanamycin-resistant derivative BR-kR. For strain G80, a characteristic well-defined aminopeptidase band, $R_{\text {fum }}$ $1 \cdot 01$, was detected. As with esterase bands, storage of extracts for $7 \mathrm{~d}$ at $-80^{\circ} \mathrm{C}$ resulted in a decrease in activity of all aminopeptidase bands from strain G80.

\section{Reproducibility of band migration}

Differentiation of strains on the basis of characteristic bands needs good band definition and reproducibility. This was obtained by growing Frankia strains under balanced conditions and by using ULGA-PAGE electrophoresis (Benoist \& Schwencke, 1990). Further, we defined the relative mobility of each band by $R_{\text {fum }}$ values. $R_{\text {fum }}$ was calculated by dividing the migration distance of a band by the migration distance of a prestained fumarase marker. Standard deviations for $R_{\text {fum }}$ values were within the range $0 \cdot 01-0 \cdot 04$, calculated from three different electrophoretograms with bands revealed by 3 indoxyl acetate and $\beta$-naphthyl propionate. Similar small variations were observed for $R_{\text {fum }}$ values when BCIA was used as substrate as well as for aminopeptidases (not shown).

\section{Discussion}

We report here that six Frankia strains isolated from the genera Casuarina, Allocasuarina and Gymnostoma, and two kanamycin-resistant derivatives, could be distinguished on the basis of the electrophoretic patterns of their esterases. With few exceptions (strains S21 and G80), aminopeptidase zymograms alone were less useful but helped to differentiate strains that showed identical or very similar esterase electrophoretic patterns.

Characterization of bacterial strains by the analysis of phenotypic characters presents the problem of reproducibility. This is especially pertinent for Frankia strains which grow slowly, non-exponentially and show morphological and physiological heterogeneity (hyphae, lysed hyphae and sporangia) under the usual static growth conditions (Benson \& Schultz, 1990). This major problem has been solved here by growing Frankia strains under controlled stirring conditions in BAP medium 

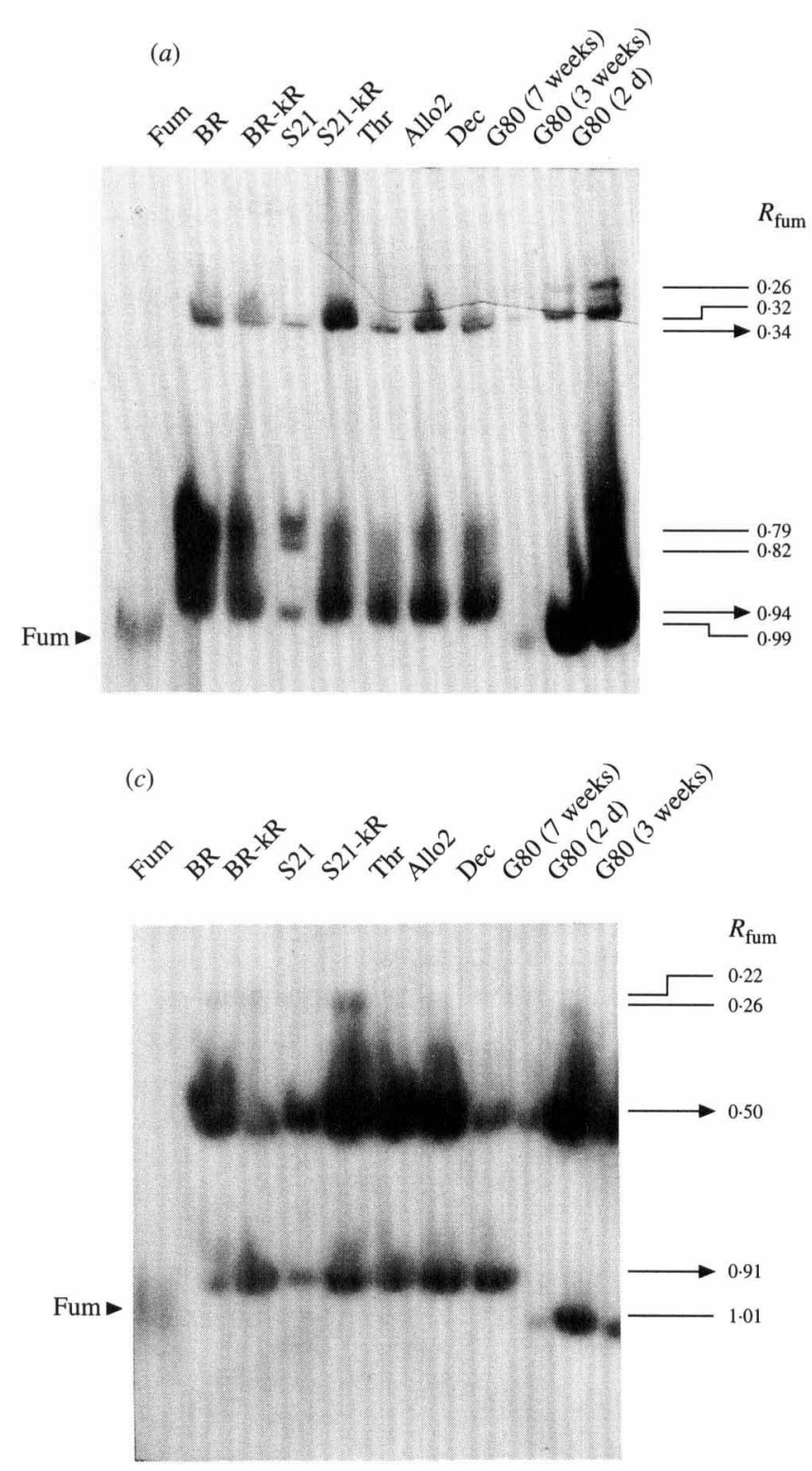

supplemented with egg yolk phosphatidylcholine. The pattern of esterases showed good reproducibility and remained unaltered along the growth curve from day 3 up to day 8 . Therefore, the zymograms obtained can be safely used to differentiate the closely related Frankia strains from the family Casuarinaceae.

A limitation to the method is that extracts cannot be stored for more than 6 to $7 \mathrm{~d}$ at $-80^{\circ} \mathrm{C}$ because esterase activities diminish as a function of storage and some bands cannot be revealed with extracts older than 1 week. This is also true for some aminopeptidases. This may be due to proteolytic degradation in the extracts. Indeed, inhibitors of the proteasome-like particles described in Frankia (Benoist et al., 1992) effectively protected esterase activities during storage (data not shown).

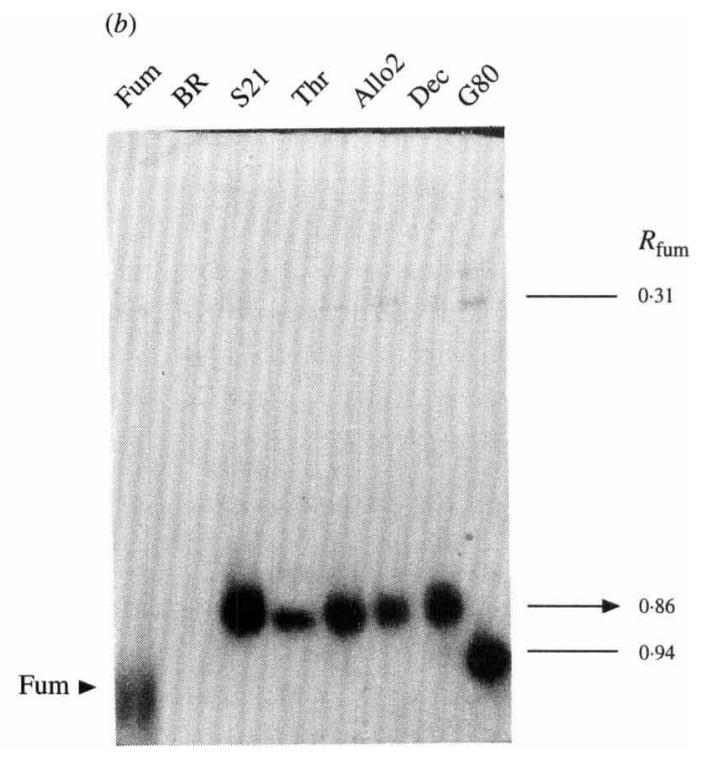

Fig. 3. Electrophoretic patterns for aminopeptidases of some Frankia stains. For each Frankia strain $250 \mu \mathrm{g}$ protein (BCA method) were loaded. Fum, $R_{\mathrm{fum}}$, as Fig. 2. (a) Electrophoresis with $50 \mu \mathrm{M}-\mathrm{CoSO}_{4}$ and incubation with $1 \mathrm{mM}-\mathrm{L}-\mathrm{Leu}-\mathrm{MNA}, 200 \mu \mathrm{M}-\mathrm{CoSO}_{4}$ and $200 \mathrm{~mm}-\mathrm{NaCl}$. (b) Electrophoresis with $50 \mu \mathrm{M}-\mathrm{ZnSO}_{4}$, and incubation with $1 \mathrm{mM}$-L-Leu-MNA, $200 \mu \mathrm{M}-\mathrm{CoSO}_{4}$ and $200 \mathrm{~mm}-\mathrm{NaCl}$. (c) Electrophoresis with $50 \mu \mathrm{M}-\mathrm{ZnSO}_{4}$, and incubation with $1 \mathrm{mM}-\mathrm{L}$-Pro-MNA, $200 \mu \mathrm{M}-\mathrm{CoSO}_{4}$ and $200 \mathrm{mM}-\mathrm{NaCl}$.

The use of the ULGA-PAGE method for electrophoretic separation of esterases under non-denaturing conditions (Benoist \& Schwencke, 1990) was essential in order to obtain both optimal activity of esterases and good band definition after electrophoresis.

Frankia strains could be distinguished by the esterase zymograms obtained using (essentially) only two different substrates: $\beta$-naphthyl propionate and 3-indoxyl acetate. The use of BCIA as substrate is described here for the first time to visualize Frankia esterases. This substrate has been used to detect esterases in mammalian tissues (Holt \& Withers, 1958). BCIA revealed a characteristic pattern of seven bands for strain G80 while only three bands were seen with either one of the other substrates. BCIA also revealed some new bands in strains from the genera Casuarina and Allocasuarina, 
complementing the information obtained with $\beta$-naphthyl propionate and 3-indoxyl acetate.

The kanamycin-resistant strains S21-kR and BR-kR could also be differentiated from their parental sensitive strains by using $\beta$-naphthyl propionate as substrate. The observed band variation may be due to kanamycinrelated alterations in gene expression or mRNA translation. However, positive selection of a naturally occurring resistant mutant cannot be excluded.

The results presented suggest that Frankia strains from the genera Casuarina and Allocasuarina, are phylogenetically very close, while strain G80 from the genus Gymnostoma is clearly separated from them. However, the general value of this preliminary conclusion should be confirmed by the analysis of esterase zymograms from other strains isolated from the genus Gymnostoma.

Until now, attempts to differentiate Frankia strains from the family Casuarinaceae have been unsuccessful. Thus, restriction analysis of DNA fragments from seven strains showed essentially identical hybridization patterns against nif $A, B, D, K$ and $H$ probes from $A l n u s$ (Nazaret et al., 1989). The use of amplified rDNA sequences showed also that strains infective for Casuarina could be grouped in a single genomic species. Other molecular approaches, such as those based on the variable, non coding section of Frankia rRNA-encoding genes (Normand et al., 1992) show promise. However, the appropriate probes are not available yet.

In conclusion, zymograms of esterase activities appear to be useful for differentiating among closely related Frankia strains by a moderately expensive and simple technique. It is clear that this method is limited to strains that can be isolated and grown under exponential growth conditions. If the method is to be applied to test strains isolated from Casuarina nodules after mixed inoculation experiments, stability of the esterase pattern for each strain after re-isolation is essential. Recent results from our laboratory indicate the patterns are stable for all strains assayed, i.e. S21, BR, Thr, S21-kR and BR-kR, opening the way for the use of esterase zymograms for identification of isolates in field studies.

The authors thank Dr A. Savoure from the Institut des Sciences Végétales CNRS, Gif-sur-Yvette, France and Dr G. Lim (now retired) from the Botany Department, National University of Singapore for providing us with Gymnostoma strain G80. We are grateful also to $\mathrm{Dr}$ H. G. Diem and Professor E. Duhoux for their continuous help and critical discussion. This research was supported by a grant from the EEC/ORSTOM project (Programme: EEC-ST2-90/0322).

\section{References}

Akkermans, A. D. L., HahN, D. \& BaKer, D. D. (1992). The family Frankiaceae. In The Prokaryotes, pp. 1068-1084. Edited by A. Balows, H. G. Trüper, M. Dworkin, W. Harder \& K.-H. Schleifer. New York: Springer-Verlag.
Baker, D. D. \& Mullin, B. C. (1992). Actinorhizal symbioses. In Biological Nitrogen Fixation, pp. 259-292. Edited by G. Stacey, R. H. Burris \& H. J. Evans. New York: Chapman \& Hall.

BfCKING, J. H. (1970). Frankiaceae fam. nov. (Actinomycetales) with one new combination and six new species of the genus Frankia Brunchhorst 1896, 174. International Journal of Systematic Bacteriology 20, 201-220.

BENOIST, P. \& SCHWENCKE, J. (1990). Native agarose-polyacrylamide gel electrophoresis allowing the detection of aminopeptidase, dehydrogenase, and esterase activities at the nanogram level: enzymatic patterns in some Frankia strains. Analytical Biochemistry 187, 337-344.

Benoist, P., Müller, A., Diem, H. G. \& SChwencke, J. (1992). Highmolecular-mass multicatalytic proteinase complexes produced by the nitrogen-fixing actinomycete Frankia strain BR. Journal of Bacteriology 174, 1495-1504.

BENSON, D. R. \& SCHULTZ, N. A. (1990). Physiology and biochemistry of Frankia in culture. In The Biology of Frankia and Actinorhizal Plants, pp. 107-127. Edited by C. R. Schwintzer \& J. D. Tjepkema. San Diego: Academic Press.

BRADFORD, M. M. (1976). A rapid and sensitive method for the quantitation of microgram quantities of proteins utilizing the principie of protein-dye binding. Analytical Biochemistry 72, 248-254.

Diem, H. G. \& Dommergues, Y. R. (1983). The isolation of Frankia from nodules of Casuarina. Canadian Journal of Botany 61, $2822-2825$.

DOMMERGUES, Y. R. (1987). The role of biological nitrogen fixation in agroforestry. In Agroforestry, a Decade of Development, pp. 245-271. Edited by H. A. Steppler \& P. K. Nau. Nairobi: ICRAF.

Fontaine, M. S., Young, P. H. \& Torrey, J. G. (1986). Effects of long-term preservation of Frankia strains on infectivity, effectivity and in vitro nitrogenase activity. Environmental Microbiology 51 , 694-698.

GARDES, M. \& LALONDE, M. (1987). Identification and subgrouping of Frankia strains using sodium dodecyl sulfate-polyacrylamide gel electrophoresis. Physiologia Plantarum 70, 237-244.

Girgis, M. G. Z., Ishac, Y.Z., El-Hadded, M., Saleh, E. A., Difm, H. G. \& Dommergues, Y. R. (1990). First report on isolation and culture of effective Casuarina-compatible strains of Frankia from Egypt. Proceedings of 2nd International Casuarina Workshop, pp. 156-164. Edited by M. H. El-Lakany, J. W. Turnbull \& J. L. Breweaker. Cairo: Desert Development Center, American University.

HoLT, S. J. \& WITHeRs, R. F. J. (1958). Studies in enzyme cytochemistry V. An appraisal of indigogenic reactions for esterase localization. Proceedings of the Royal Society of London Series BBiological Sciences 148, 520-534.

Jolnson, L. A. S. (1988). Notes on Casuarinaceae. III. The new genus Ceuthostoma. Telopea 3, 133-137.

Lalonde, M. \& Calvert, H. E. (1979). Production of Frankia hyphae and spores as an infective inoculant for Alnus species. In Symbiotic Nitrogen Fixation in the Management of Temperate Forests, pp. 95-110. Edited by G. C. Gordon, C. T. Wheeler \& D. A. Perry. Corvallis: Oregon State University.

Lalonde, M., Calvert, H. E. \& Pine, S. (1981). Isolation and use of Frankia strains in actinorhizae formation. In Current Perspectives in Nitrogen Fixation, pp. 296-299. Edited by A. H. Gibson \& W. E. Newton. Canberra: Australian Academy of Sciences.

Mirza, M. S., Janse, J. D., HAHN, D. \& AKKeRmans, A. D. L. (1991). Identification of atypical Frankia strains by fatty acid analysis. FEMS Microbiology Letters 83, 91-98.

Müller, A., Benoist, P., Diem, H. G. \& SChWencke, J. (1991). Agedependent changes in extracellular proteins, aminopeptidase and proteinase activities in Frankia isolate BR. Journal of General Microbiology 137, 2787-2796.

Nazaret', S., Simonet, P., Normand, P. \& Bardin, R. (1989). Genetic diversity among Frankia isolated from Casuarina nodules. Plant and Soil 118, 241-247.

Normand, P., Cournoyer, B., Simonet, P. \& Nazaret, S. (1992). Analysis of a ribosomal RNA operon in the actinomycete Frankia. Gene 111, 119-124. 
Prin, Y., Maggia, L., Picard, B., Diem, H. G. \& Gotlleet, P. (1990) Electrophoretic comparison of enzymes from 22 single-spore cultures obtained from Frankia strain ORS 140102. FEMS Microbiology Letters 77, 223-228.

SCHWENCKE, J. (1991). Rapid growth and increase biomass yield for some Frankia strains in buffered, stirred mineral medium (BAP) with phosphatidylcholines. Plant and Soil 137, 37-41.

Simonet, P., Normand, P., Molroud, A. \& BARdin, R. (1990).
Identification of Frankia strains in nodules by hybridization of polymerase chain reaction products with strain-specific oligonucleotide probes. Archives of Microbiology 153, 235-240.

Sougoufara, B. (1990). La fixation de $\mathrm{N}_{2}$ par les Casuarinas: amélioration par sélection clonale et quantification par differentes méthodes. Thèse Docteur d'Université de Nancy I, France.

TORreY, J. G. (1978). Nitrogen fixation by actinomycete-nodulated angiosperms. BioScience 28, 586-592. 